\title{
Influence of constructed wetland water quality based on the ecological design and restoration project
}

\author{
Tai-Hai Xu, Guo-Fa Zhang, Yan-Tao Liang, \\ Zhi-He Qiao and Shu-Kui Zhao \\ Daqing Normal University, Daqing, \\ Heilongjiang, China \\ Tai-Hai Xu \\ E-mail:xutaihai1019@126.com
}

\begin{abstract}
The ecological design projects of different levels were carried out at the demonstration area. From 2013 to 2015, the dynamic monitoring of the demonstration zone water quality was carried out: the background information of wetland was investigated in 2013; two wetlands with serious pollution were selected as the research object in the 2014; ecological projects were full implemented in the demonstration area in 2015. Water quality was researched; analyze the water quality improvement after ecological engineering implementation. Results show that in 2014, the two indicators of COD and $\mathrm{BOD}_{5}$ decreased significantly in the I and II ecological restoration projects, but degradation of $\mathrm{N}$ and $\mathrm{P}$ was not obvious; in 2015, with the full implementation of ecological engineering measures, wetland water quality has been improved.
\end{abstract}

Keywords: Wetlands; Ecological Design; Ecological Engineering; Water Quality.

\section{Introduction}

Sewage, livestock and poultry breeding, industrial effluent and so on lead nutrients such as nitrogen and phosphorus in the rivers, lakes and other water accumulation, causing eutrophication nearly 30 years[1], wetland has certain purging effects[2], sewage purification effect of constructed wetland is affected by many factors[3]. When the pollution reaches a certain level, it will also pose a threat to the wetland ecosystem environment.

Wetland ecological restoration technology mainly has 3 aspects: wetland habitat restoration technology, wetland biological restoration technology, wetland ecosystem structure and function restoration technology [4-5]. Research and practice of wetland restoration work carried out in some cities of China

\footnotetext{
"Supported by the "Dr. Start-up Research Fund of Daqing Normal University (11ZR19)"
} 
since 1980s [6]. In the over past 30 years, several of damaged wetland restoration technologies were formed [7]. The techniques to purify polluted water are so abundant, such as using aquatic plant [8], combined ecological floating bed technology [9], Water conservancy construction project [10], biological control technology [11], watershed management methods [12], and so on. Water quality is an important factor that affects the ecological environment of the wetland, it is important to research the influence of ecological engineering design on water quality.

\section{Methods of Ecological Restoration Engineering Design}

Using the theories and methods of landscape ecology and environmental ecology, to carry out the ecological engineering design of different levels, to further promote the restoration of artificial wetland and optimization of ecological environment.

\subsection{Selection of demonstration area}

Select the Daqing Oilfield Mining Area Wetland as the research demonstration area. Currently, the main problems of Daqing oilfield wetland ecosystems of the main problems is the reduction of the wetland area, wetland degradation, contamination of some wetlands and fragmentation of the wetland landscape type, etc. The main features of the oilfield groups of lakes and wetlands are characterized by a large number of ponds and lakes, small and shallow ponds and lakes of which most are below $1000 \mathrm{hm}^{2}$. Such wetland ecosystems are poor in stability and prone to change when disturbed.

\subsection{Green Design of the Gemonstration Area}

In order to practice the green design, considering about such kind of structure characteristics and natural laws, we propose the ecological restoration guideline as "Planting trees in the high ground, storing water in the lower parts, leaving the naturally growing reeds in the transition zone".

\subsection{Comprehensive Ecological Projects}

Ecological projects should be adjusted differently to local conditions in the restoration of impaired wetland in the oilfield, such as "lake connection and water storage project", "pit management project", "grassland virescence project", "project for treating polluted wetlands" and so on. 


\section{Sampling and Monitoring Method}

\subsection{Sampling point description}

2013: XA--small gourd lake before the treatment, ZA--three new South Station lakes before the treatment.

2014: Constructed wetland with surrounding lake bubble replenishment, where the sampling points IS1, IIS1 are two inlet of demonstration area, IS2, IIS2 respectively are the two sampling points of two sets of ecological restoration engineering measures after the implementation of I and II, SZ is the lowest point after ecological restoration engineering measures implementation, which is the last place of all the water inlet, when the water does not affect oil production, the amount of water will gradually reduce due to the natural evaporation and groundwater infiltration and other forms, when the amount of water is too high, SZ sampling points with pump, through the water pump provided the water into the drainage canal that discharge demonstration zone.

2015: XA-small Gourd Lake after the treatment, ZA-three new South Station Lake after the treatment.

\subsection{Monitoring methods}

$\mathrm{COD}$ was monitored by dichromate titration, $\mathrm{BOD}_{5}$ was monitored by dilution and inoculation method; TP was monitored by spectrophotometric determination of molybdenum and ammonia; TN was monitored by Alkaline potassium sulfate digestion UV spectrophotometry.

\section{Ecological Restoration Effects}

\subsection{Sampling annual design and monitoring results}

Background information of the wetland was researched in 2013; wetland with heavy pollution was selected as the research object in 2014; full implementation of ecological restoration projects in the demonstration area in 2015, research repairing effect of the whole research area after the ecological restoration engineering implementation. The wetland water sampled 4 times every year, the determination results are shown in Table 1. 
Table 1. Statistical table of monitoring results of Ecological Construction Demonstration Area

\begin{tabular}{|c|c|c|c|c|c|c|}
\hline $\begin{array}{l}\text { Serial } \\
\text { numbers }\end{array}$ & $\begin{array}{l}\text { Sampling } \\
\text { position }\end{array}$ & $\begin{array}{l}\text { Year of } \\
\text { sampling }\end{array}$ & $\begin{array}{l}\text { COD } \\
(\mathrm{mg} / \mathrm{L})\end{array}$ & $\begin{array}{l}\mathrm{BOD}_{5} \\
(\mathrm{mg} / \mathrm{L})\end{array}$ & $\begin{array}{l}\text { TP } \\
(\mathrm{mg} / \mathrm{L})\end{array}$ & $\begin{array}{l}\mathrm{TN} \\
(\mathrm{mg} / \mathrm{L})\end{array}$ \\
\hline 1 & $\mathrm{XA}$ & \multirow{2}{*}{2013} & $56-86$ & $6.2-7.8$ & $0.11-0.18$ & $0.54-1.06$ \\
\hline 2 & $\mathrm{ZA}$ & & $68-98$ & $6.3-7.9$ & $0.13-0.19$ & $0.73-1.02$ \\
\hline 3 & IS1 & \multirow{5}{*}{2014} & $79-121$ & $7.0-16.0$ & $0.26-0.35$ & $0.95-1.69$ \\
\hline 4 & IS2 & & $76-112$ & $7.0-12.0$ & $0.18-0.40$ & $0.83-1.98$ \\
\hline 5 & IIS1 & & $79-137$ & $7.0-16.0$ & $0.12-0.40$ & $0.65-1.69$ \\
\hline 6 & IIS2 & & 66-102 & $7.0-12.0$ & $0.06-0.36$ & $0.91-1.96$ \\
\hline 7 & $\mathrm{SZ}$ & & $75-121$ & $8.0-14.0$ & $0.17-0.50$ & $0.84-2.36$ \\
\hline 8 & $\mathrm{XB}$ & \multirow{2}{*}{2015} & $31-40$ & $<2.0-2.6$ & $<0.01-0.03$ & $0.32-0.46$ \\
\hline 9 & $\mathrm{ZB}$ & & $28-38$ & $<2.0$ & $<0.01-0.03$ & $0.34-0.48$ \\
\hline
\end{tabular}

\subsection{Analysis of Heavy Pollution Area Ecological Restoration Demonstration Project Effect in 2014}

The detection index including four indicators such as $\mathrm{COD}, \mathrm{BOD}_{5}, \mathrm{TN}, \mathrm{TP}$. Ecological restoration project turn down the pollutants concentration of COD and $\mathrm{BOD}_{5}$ significantly, but influence on the pollutants concentration of TN and TP are uncertain. The results are shown in Figure 1.

COD
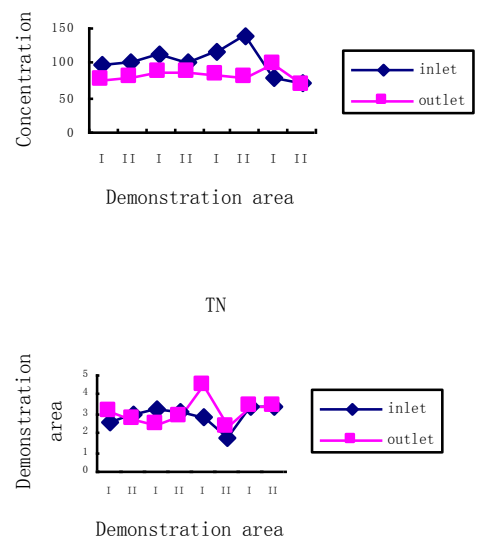

$\mathrm{BOD}$
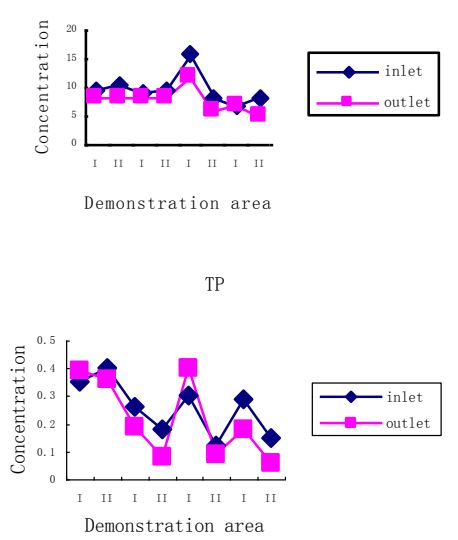

Fig. 1. Pollutants concentration changing in the Ecological Construction Demonstration Area.

\subsection{The effects of implementation of ecological restoration in 2015}

According to the implementation of ecological engineering, the wetland water quality was improved obviously by the implementation of ecological engineering in 2015. Due to the full implementation of the ecological engineering measures in 2015, water quality improvement effect was better then the effect in 2014, but because of the ecological engineering design mainly 
depend on water conservancy engineering and plant restoration, the effects were limited.

\section{Conclusion}

Effects of ecological restoration engineering on artificial wetland ecosystem is various, combined with the wetland ecological construction project of Daqing Oilfield, summarize and analyze the effect of ecological restoration engineering on artificial wetland water quality, provide certain theoretical basis for wetland management. However, the effect of water quality improvement by ecological engineering need for a certain period of time, all the problems would not shown in short-term (1-2 years), during the research process in the future, we should also strengthen wetland management and fixed-point observation, to form a relatively complete theory and wetland management system.

\section{Reference}

1. LIU Guo-feng, BAO Xian-ming, WU Ting-ting, HAN Shi-qun, XIAO Min, YAN Shao-hua, ZHOU Qing. Purification of Water in Zhushan Bay of Taihu Lake with Water Hyacinth Ecological Engineering. Journal of Agro-Environment Science, 2015, 34(2): 352-360(In Chinese).

2. XIONG Jia-qing, DU Chen, ZHENG Yu-cong, GE Yuan, WANG Yi-wen, WANG Xiao-chang. Design of Constructed Wetland System for Ecological Purification of Polluted River Water Qualit. China Water \& Wastewater, 2014, 24:89-92. (In Chinese)

3. Hao Shengjie, Wu Rongfang, Zhang Jian, Zhang Lei. Study on the Influence Factors of the Artificial Wetland Restoration and Regeneration Water Landscape Water Body. Heilongjiang science and technology information, 2014, 05:232. (In Chinese)

4. 4. LI Xiang-qun, HUANG Xiao-shi, YE Lan-xin. Development and Construction of wetland Ecological Engineertin. Times Agricultural Machinery, 2015, 54(8):167-169. (In Chinese)

5. WANG Jinshuang. Research Progress on Technology of Wetland Ecological Restoration. Agricultural Science \&Technology and Equipment, 2015, 09:13-15. (In Chinese)

6. Xu Muqi, Huang Yuyao. Restoration and Reestablishment of the Damaged Ecosystem of inland waters. Acta Ecologica Sinica, 1998, 18(5):547-557. (In Chinese)

7. QIAO Zhi-he, ZHAO Shu-kui, LIANG Yan-tao. Restoration of Damaged Wetlands in Daqing Oilfield based on Pan Green Design Wetland Science, 2012, 10(3):312-317. (In Chinese) 
8. DAI Yunv, WU Pengju, YANG Yang, CHI Yihan, LIAO Lingjuan, QIAO Yongmin. Impact of Aquatic Macrophyte Restoration on Water Quality Improvement in Dongguan Ecological Industrial Park. Ecology and Environmental Sciences, 2014, 23(9): 1463-1471. (In Chinese)

9. HU Kai-quan, ZENG Dong, XU Zhen-cheng, WEI Dong-yang, MA Xiao-zhou, ZHANG Xiao-dong, HU Kuang-cheng, YAN Xiong-feng.Operation Effect of In-situ Ecological Restoration Demonstration Project in Tonghu Area. China Water \& Wastewater, 2015, 23:15-19. (In Chinese)

10. JU Yong-fu, YU Ting, Ren Lei. Analysis of Chenghei Marsh Restoration Scheme on Small Xingkai Lake Heilongjiang Science and Technology of Water Conservancy, 2015, 08:49-53. (In Chinese)

11. LI Xing-ping. Study on Ecological Rehabilitation of Urban Landscape Water. Sichuan Environment, 2015, 01:133-137. (In Chinese)

12. Zhang Guangping, Jiang Liming. Technology of Eutrophic Water Treatment. Modern Metallurgy, 2014, 06:72-75. (In Chinese) 